\title{
Biomimetics as problem-solving, creativity and innovation tool
}

\author{
Marjan Eggermont \\ Schulich School of Engineering, University of Calgary \\ meggermo@ucalgary.ca
}

\begin{abstract}
Engineering sketching, as taught in our first-year design course, exists somewhere between writing and formal drawing as a means of formulating ideas. In our third year of teaching engineering sketching assignments were given several additional components: the visualization of engineering concepts, sustainable product design and biomimetics. This was done for a number of reasons:

- Students were given the opportunity to integrate knowledge from other first year engineering courses

- $\quad$ Students were challenged to think spatially, socially and philosophically (but not always in that order)

- Students who were not necessarily strong artists felt they could make up for this in the 'additional component' category

- First year students seem to have a great interest in the study of structural biology as it applies to engineering design.
\end{abstract}

Now in our fifth year, this paper discusses biomimetics, the abstraction of good design from nature, the transfer of technological ideas from nature to artificial applications, and the resulting student projects.

\section{Introduction}

Biomimetics offers an interesting approach to design in our current political environment of sustainable design and sustainable design solutions (even 'ecofriendly fire'). Biomimetics is a "multi-disciplinary subject involving a wide diversity of other domains like electronics, informatics, medicine, biology, chemistry, physics, mathematics, art and many others. The process of biomimetics itself is interesting, relying on the fact that living organisms and engineers have a similar goal: to create a structure in the cheapest way possible - either in terms of energy or money [1]."

This multidisciplinary approach impresses upon novice designers the importance of teamwork; it also explores a topic that lends itself easily to be co-taught across faculties.

Biomimetics, as taught in our course, is introduced starting with historical examples such as the Crystal Palace, barbed wire, Velcro and ending with more recent examples such as spider silk produced in goat's milk, Lotusan paint, the Beijing Olympic Swim stadium, termite mound inspired architecture, Gecko tape, and more.

Students use engineering sketching and the latest biomimetic research to come up with solutions for everyday activities, objects and environments. This paper will also discuss some of the many designs that have resulted from these projects.

\section{A brief history of biomimetics}

Man has always drawn on nature for inspiration. Leonardo Da Vinci designed ships based on the shapes of fish and planes based on the wings of birds, but it wasn't until the Wright brothers observed the fact that birds glide and do not flap their wings repeatedly that a somewhat successful plane was designed. Two famous biomimetic structures are the Victorian Crystal Palace and the Eiffel tower. The Crystal Palace, an eighteen acre glass and iron construction, was designed and built in 1851 to house the Great Exhibition. Botanist Joseph Paxton designed the structure based on his studies of the water lily, victoria amazonica, which could hold the weight of a small child. Paxton designed a ribbed iron support structure for the large glass panes based on the underside of the lily leaves. Gustave Eiffel built his structure based on research done by Hermann Von Meyer, an anatomist and engineer Karl Cullman. Von Meyer and Cullman had studied the head of the femur and the lattice of ridges within the femur which made the shape perfect for supporting off-centre loads. Eiffel used a series of wrought iron braces and studs to reproduce the structure of the femur [2]. 
Biomimetics from the Greek bios (life) and mimesis (imitation) is a term that was first coined in 1950 by Otto Schmidt, an American engineer. Many areas of engineering before and after 1950 could and can be considered biomimicry in some form. In Fig. 1 we can see the many different levels at which biomimicry can be explored.

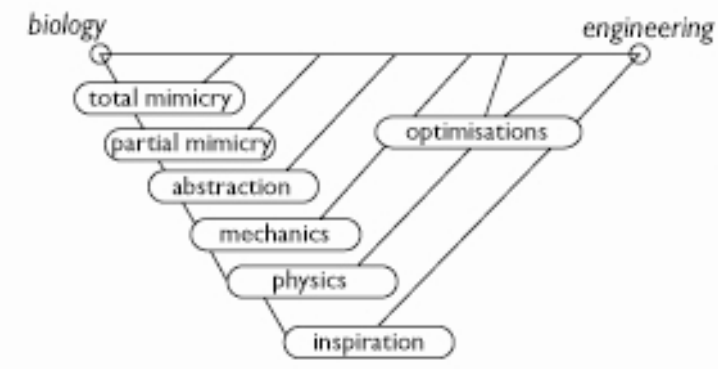

Figure 1. Links between biology and engineering from Julien Vincent's Stealing Ideas from Nature

In our first-year course the students look at fairly 'visible' levels of biomimicry. In an ideal world all first year students would have to take a structural biology course which would give them a real insight into solving problems. A structural biology course could explain the natural world on three levels:

- Nature as model. Biomimicry can imitate or take inspiration from nature's designs and processes to solve human problems. Structural biology could show many realworld examples illustrating concepts learned in physics and mathematics. It could serve as a bridge between engineering and sciences.

- Nature as measure. Biomimicry shows an ecological standard to judge the 'rightness' of our innovations: What works; what is appropriate; what lasts.

- Nature as mentor. The model of extracting from nature is extremely outdated. Our current levels of expertise can easily be redirected to learn from nature and create models that are sustainable, not finite [3].

The next section will briefly discuss the different levels of biomimicry, which can be explored in the realm of biology and engineering as suggested by Vincent. It is interesting that most attempts at biomimicry still seem to require a large component of realism or 'total mimicry'. A parallel can be drawn to the art world: a majority of people still prefer to see high realism in painting and drawing, even though the invention of photography should have cured that preference over a hundred years ago. The most recent example of this is the Battlefield Extraction Assist Robot (BEAR) [Fig. 2], a robot that is supposed to rescue wounded soldiers from the battlefield. It has a head shaped like a teddy bear to suggest comfort [4]. The BEAR seems ill prepared to deal with potential missing limbs.

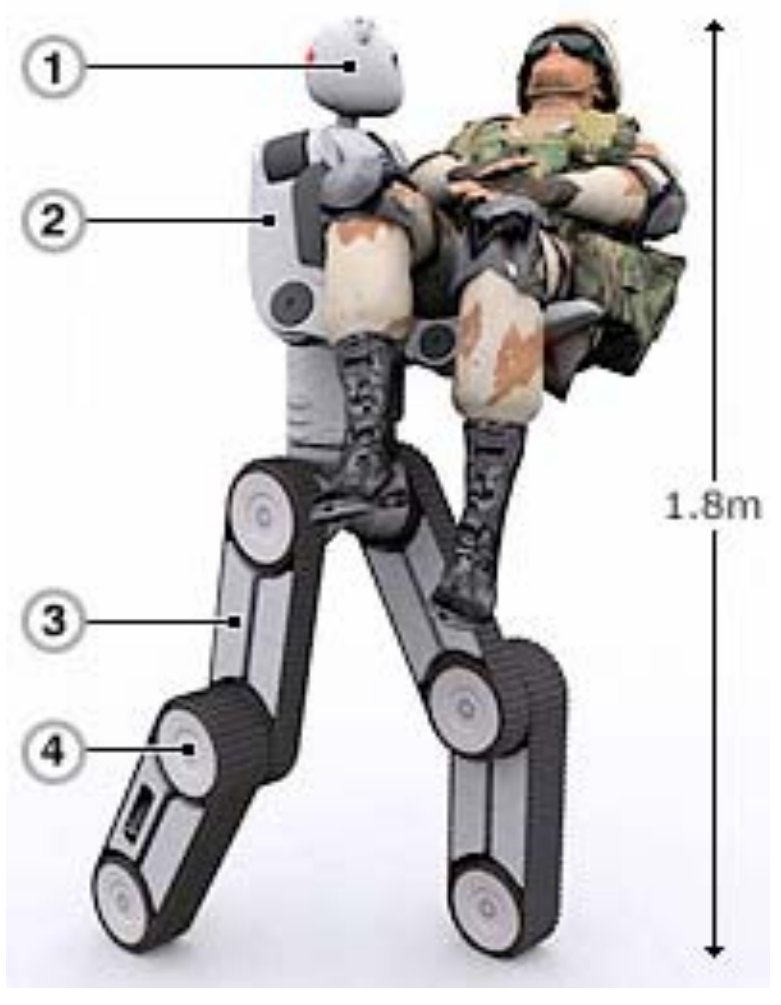

Figure 2. BEAR

\section{Levels of biomimetics}

As mentioned previously our students look primarily at the 'visible' levels of biomimicry. These are levels that deal with total or partial mimicry, which can be observed by looking at external characteristics. This comes as no surprise since a much more in depth study of biology is required to be able to delve deeper into abstraction and the mimicry of, for example, chemical systems. This next section will look at the levels noted in Figure 1 and will give biomimetic examples that fit in each category. The levels represent phases of abstraction that require more knowledge as one moves from the upper left to the lower right in the figure.

Total mimicry aims to duplicate an organism completely - most biomimetic examples can be placed in this category. Sangbae Kim's Stickybot is an 
example of a robot that mimics a gecko and its ability to climb a vertical surface [Fig. 3].

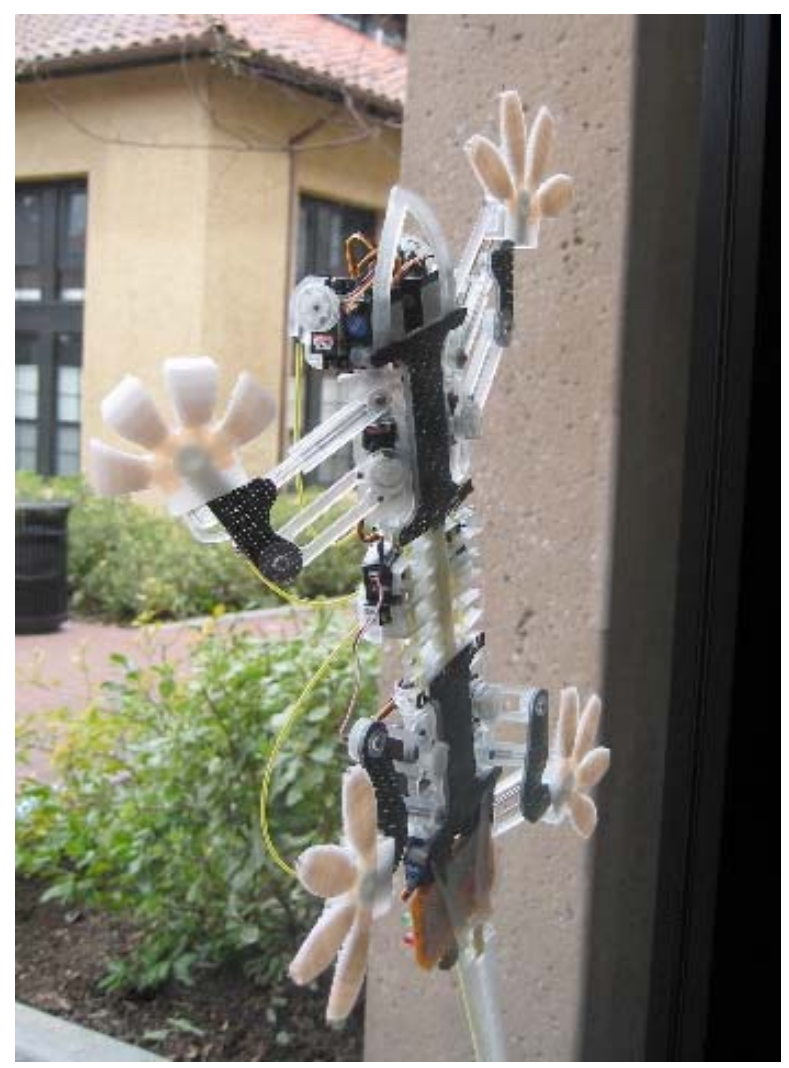

Figure 3. Sangbae Kim's Stickybot

ReplieeQ1 is an even more extreme attempt at total mimicry [Fig. 4]. This is the ultimate high realism robot, but even the researcher/creator of this robot admits that this level of realism becomes 'creepy'. The subtleties of this robot are technically impressive, but perhaps perfectly simulating a human is, in the end, creating nothing new.
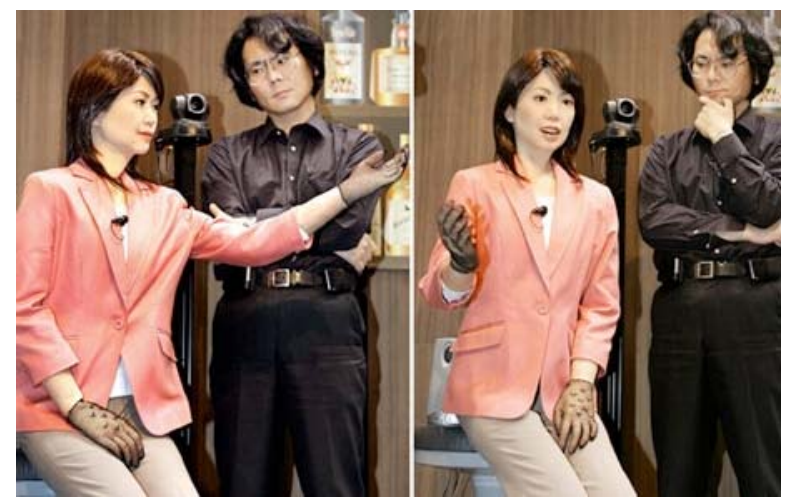

Figure 4. ReplieeQ1
Partial mimicry, also in the shape of a humanoid, is Honda's Asimo, a robot designed to assist people in every day mundane tasks.

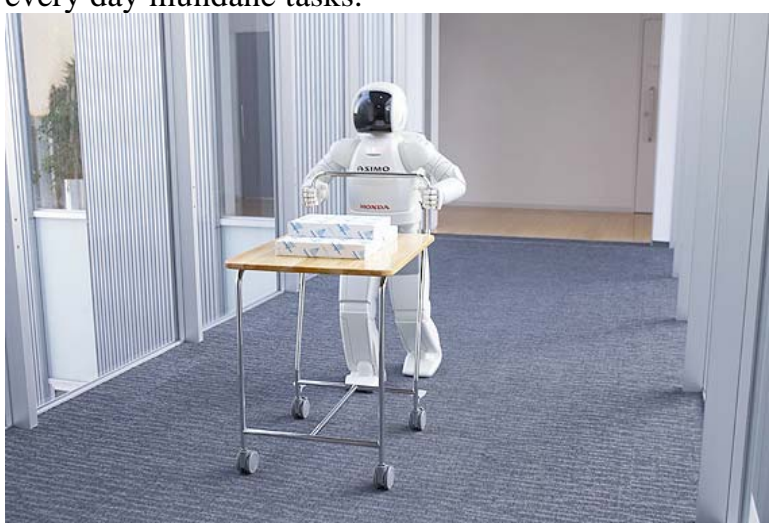

Figure 5. Asimo

The third level of biomimicry, abstraction, can be seen in the design of blended winglets designed to reduce fuel consumption in powered aircraft and increase cross-country speed in gliders. These blended winglets are an abstraction from the wingtips found in several species of birds [Fig. 6].

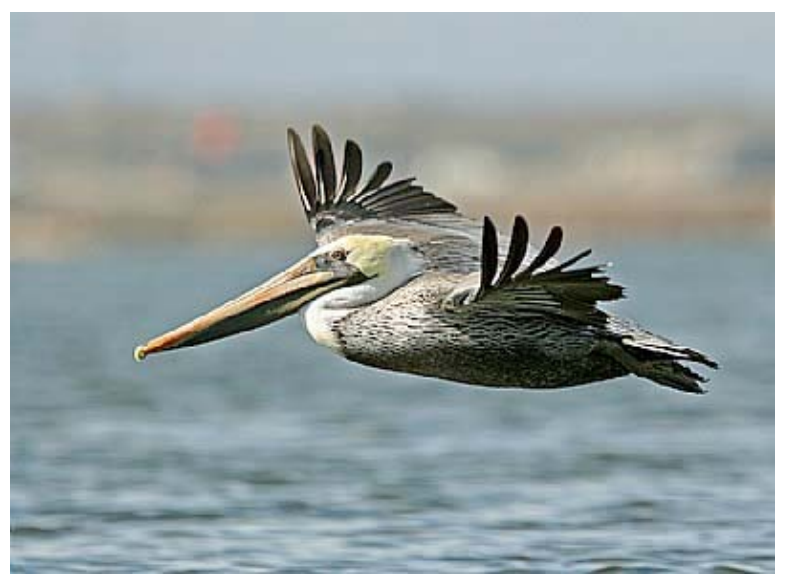

Figure 6. Inspiration for blended winglets

Another area of abstraction is a self-replicating robot from Cornell University: "Each cube contains a microprocessor, a motor, and electromagnets. The magnets selectively weaken and strengthen connections between other cubes, thereby determining where the structure breaks and joins. The growing cube assemblies are supplied with extra cubes at two "feeding" locations. A three-module robot can replicate itself in just over a minute." [5]

The robot is based on biological models of selfreproduction. The building blocks for the robots still have to be provided by their creators. The movement 
of the robot is based on sequential movements of 45 degrees and manages to be elegant at the same time - a good example of an abstract system that does not rely on elegance by adding an external recognizable veneer. Form, in this case, follows function.

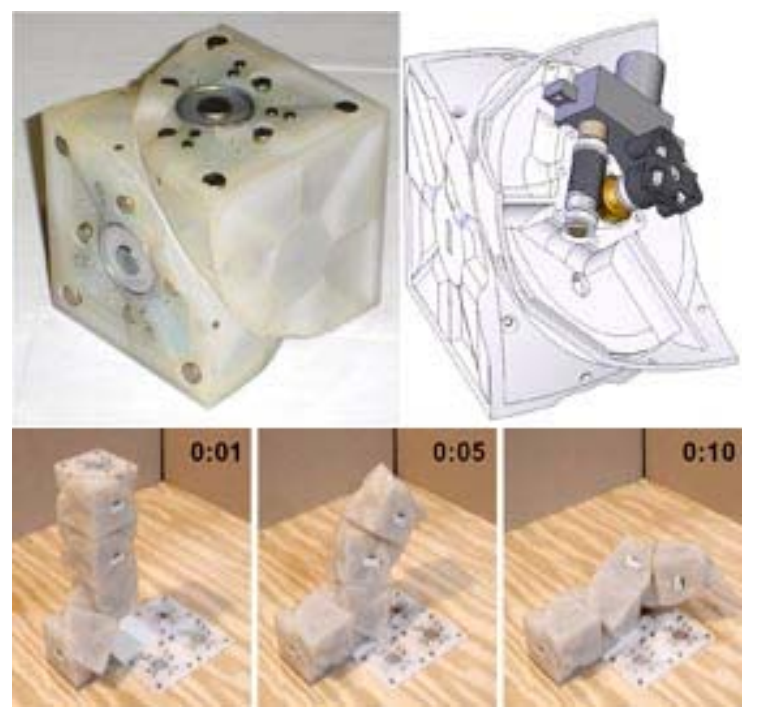

Figure 7. Self-replicating robot

The new Beijing Olympic swim stadium could fit the level of mechanics and possibly physics. The walls duplicate the mechanics of the 'wall' of a soap bubble. Visually the building can be considered partial mimicry as the surface duplicates the look of soap. In the background the main stadium can be seen designed in the shape of a bird's nest: partial mimicry and in this case chosen as cultural signifier.

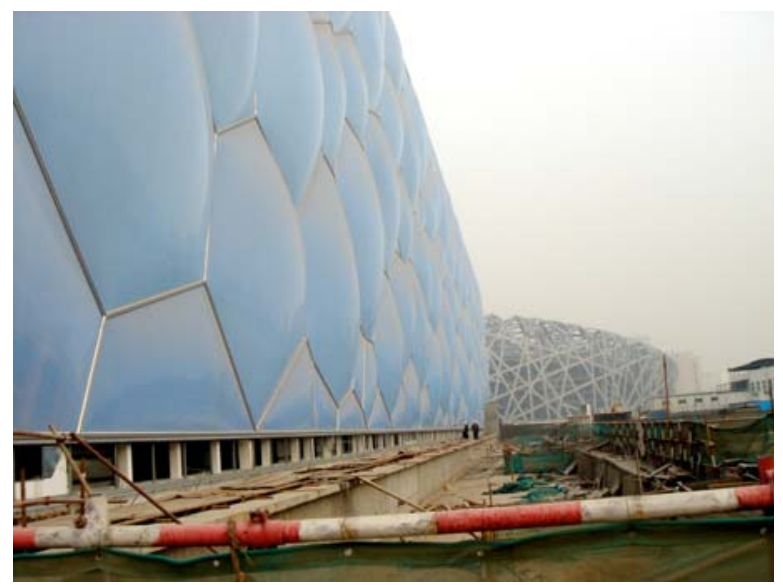

Figure 8. The Beijing Olympic Water cube under construction, with the main stadium (Bird nest) in the background
The next section will take a closer look at three years of biomimetics assignments and the changing nature of these assignments.

\section{Three years of biomimetics in first year design}

An introduction to biomimetics and the discussion of research areas currently expanding in this field can generate a lot of enthusiasm among first year students. The biological aspects turn engineering concepts into more tangible examples. The students also feel this is an area of growth and potential new discoveries. In the current climate of sustainable design, biomimetics is an area that promises real change. Sustainable design is easily explained when using biomimetics as teaching model. Students understand that the natural world:

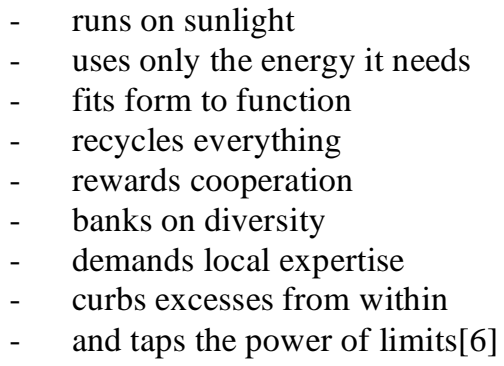

This area also invites a great deal of creativity. Students have to observe, process, analyze and synthesize different types of information.

The first biomimetic assignment was completed in 2004/2005. It required external observation of organisms and required some mechanical abstraction:

\section{"Design Problem: BIOMI METIC Hand Tool}

Design a biomimetic hand tool that executes one of the following actions:

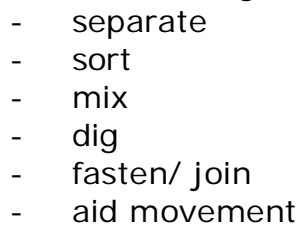

Design a tool with a new function (a reasonable and potentially workable function) or redesign an existing tool. The following questions are things to think about:

- What problem are you trying to solve? 
- What kind of tool are you thinking about?

- What does the tool do?

- Which natural systems or organisms solve your problem?

- How does nature deal with the natural laws that concern your 'problem'?

- Find as many biological examples as you can that deal with your problem, then choose the one that will help you most.

Please avoid a physical likeness to your source - your drawing should look like a tool, NOT like a fuzzy creature with ears and a tail that also happens to cut things in half."

Two results can be seen below:

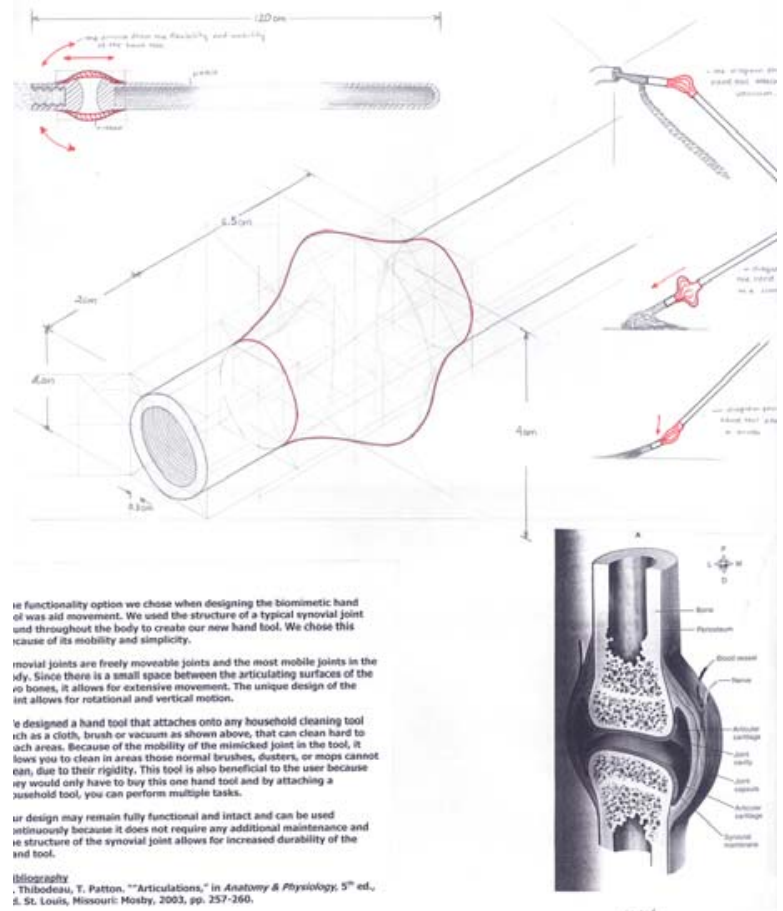

Figure 9. Flexible handle based on tendons student work

Students were asked to look at the mechanical workings of organisms or parts of organisms. These mechanisms were then applied to implements used for everyday tasks. In the example above, a student created a flexible joint after researching tendons.

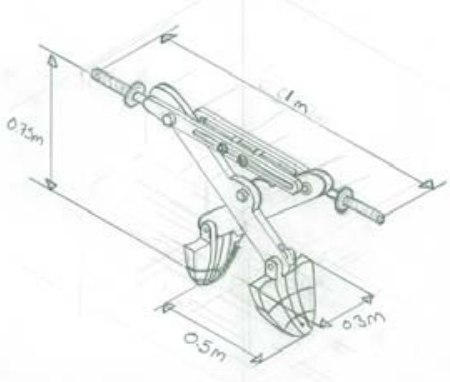

\section{Turbo Mole: 21st Century Shovel}

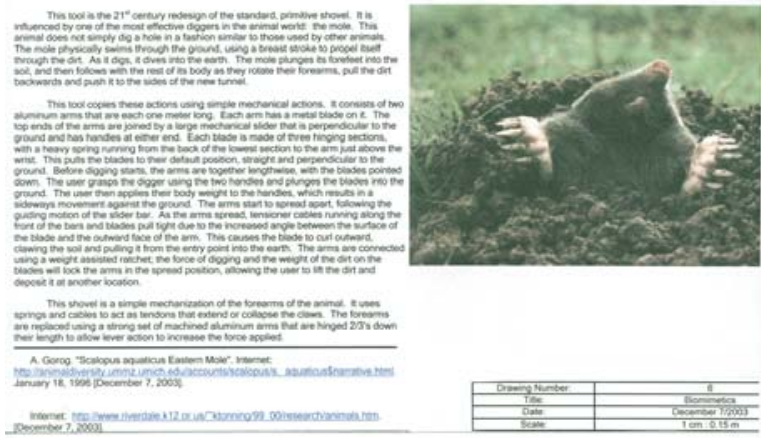

Figure 10. Shovel based on mole - student
work

Students did a reasonable job researching and drawing their 'subject' and object, and tried to sell the resulting project to the instructor with slogans such as: "Housewives, fear no more! Turbo mole is here!"

In 2005/2006 the assignment became more focussed. Students were asked to research insect senses and/or locomotion and were asked to improve or redesign a device focussing on sustainable solutions.

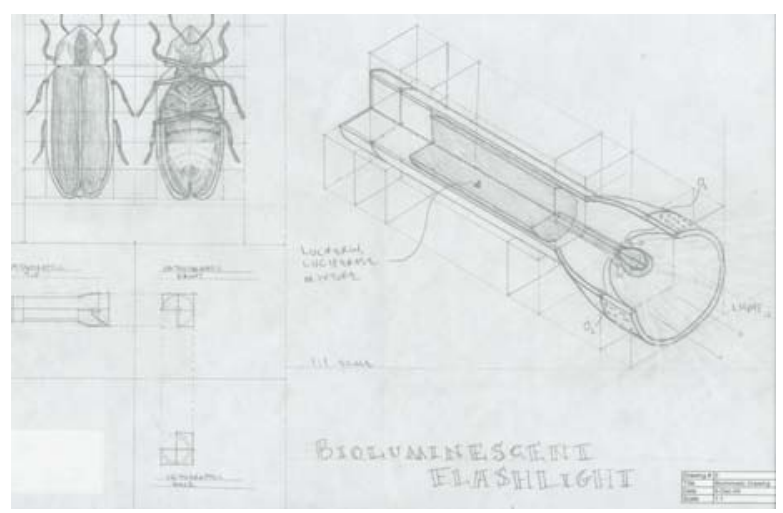

Figure 11. Bioluminescent flashlight 


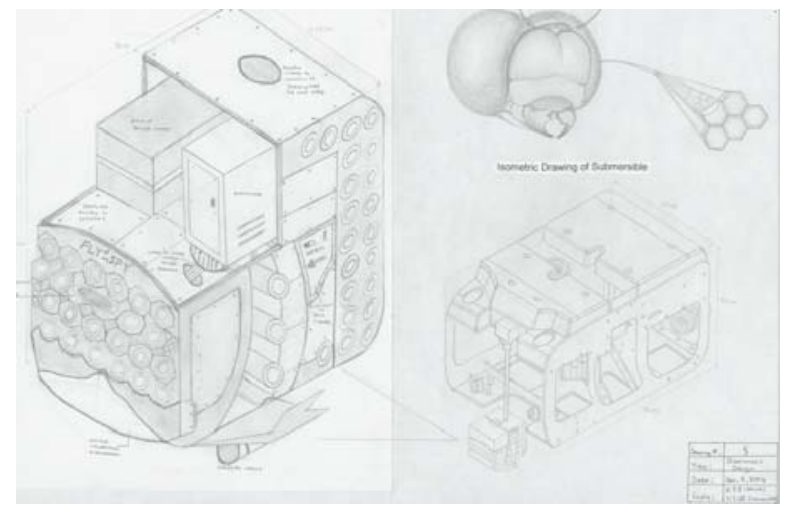

Figure 12. Window based on compound apposition insect eyes

This past year students worked with a large biomimetic database that contained 150 pages of scientific research and descriptions of structural biology phenomena. For example:

\section{Taprooting}

Type of Phenomenon:

\section{Pattern}

Level of Phenomenon: Individual Organism

Source of Phenomenon:

\section{Biological}

Description:

A taproot is, as its name implies, a main root that burrows almost vertically down into the soil to stabilize the tree in high winds.

Because it is a continuation of the trunk downward into the soil, the stiff taproot essentially resists lateral forces applied to the above-ground tree by "pushing back" against the soil in the opposite direction. Further stability is provided by ramifying lateral roots that extend outward near the soil surface (Vogel 1996). Stiffness, or resistance to bend, along with sufficient breadth, or "broad-side" area, are critical features in taproots: too much flexion decreases above-ground stability, while a too-narrow root may penetrate sideways through the soil rather than "pushing" against it (Vogel 1996).

The limber pine is one example of an organism that has put the taproot to good use. The pine thrives in windswept areas due in large part to the anchoring of its tough, thick taproot.

Further study of the taproot's structure, composition, and trunk-root relationship may lead to innovations in building foundations, columns, piles and caissons, and other structural support elements [7].

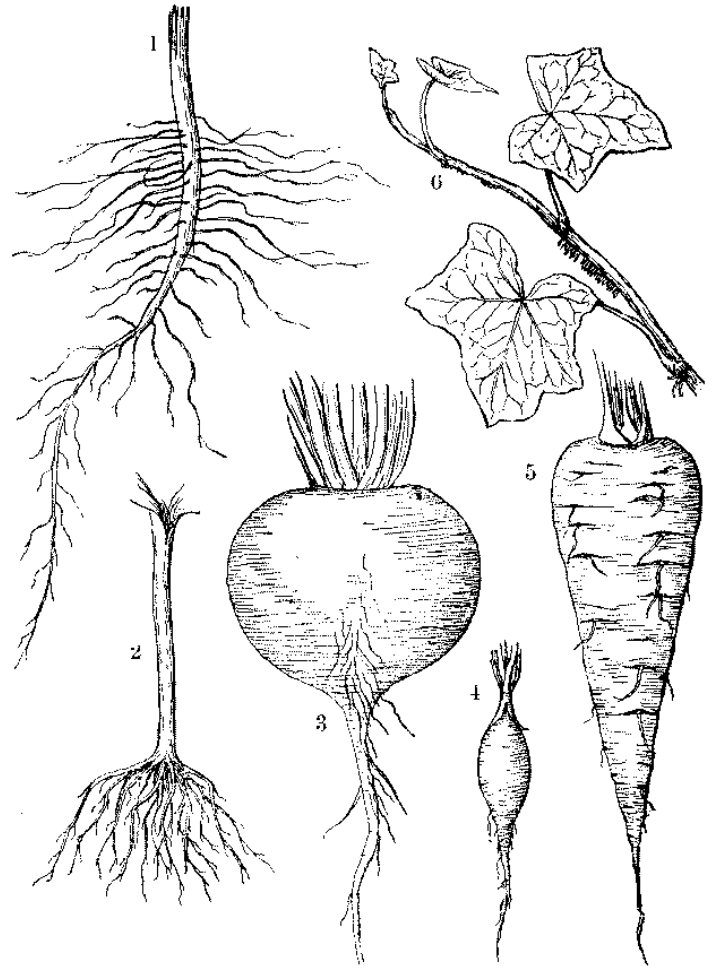

Figure 13. Taproots [8]

Based on this extensive material, ranging from heat transfer to mechanical systems, students were asked to suggest improvements to a house or apartment building. The access to the structural biology document allowed the students to get much deeper into levels of abstraction. Results of this assignment were much better than the previous two years.

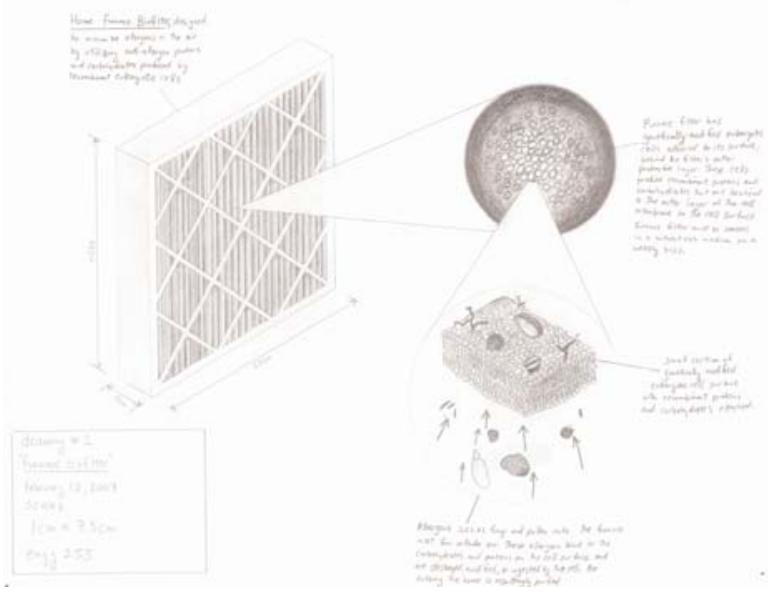

Figure 10. Air filter based on cell structure 


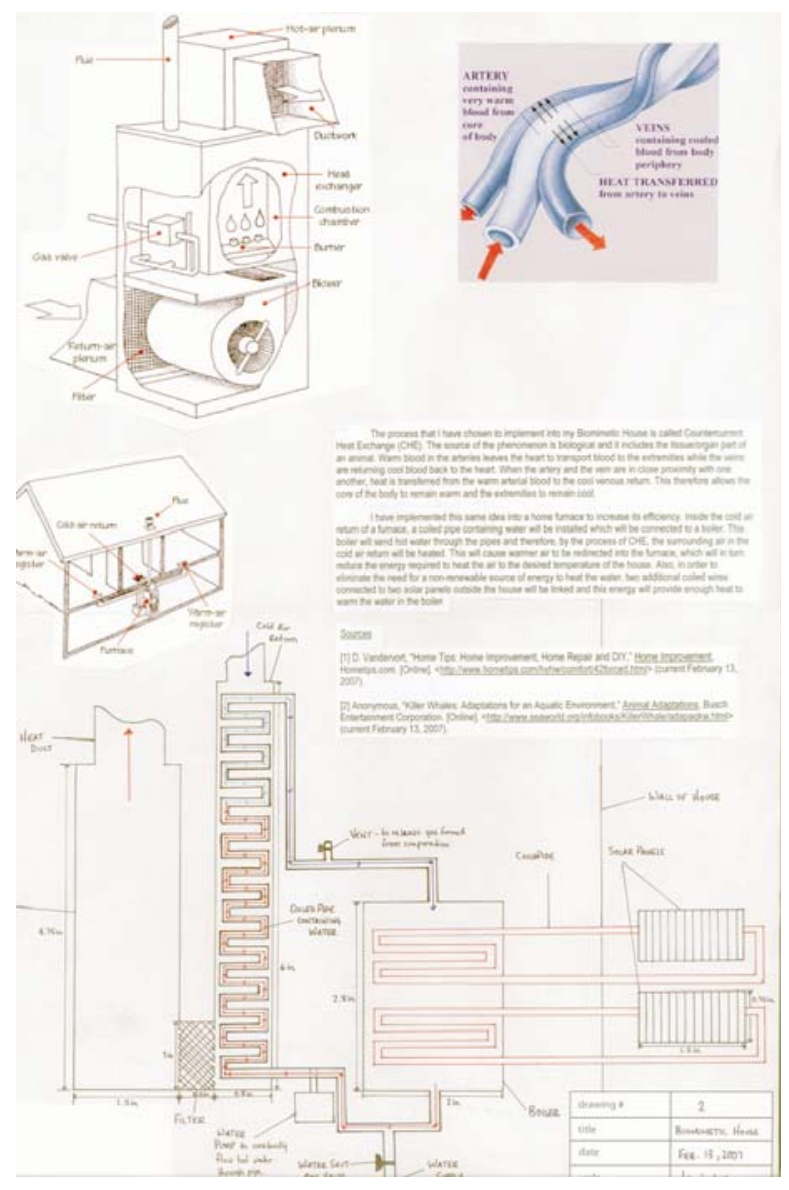

Figure 14. Domestic counter current heat exchange based on arteries

The access to scientific data made the assignment very real. Students did not feel they were 'making things up'. They felt they were researching a real solution: making connections between their math, physics and engineering design course to create tangible solutions.

\section{Conclusion}

Biomimetics, or the abstraction of good design from nature, has become a permanent fixture in our first year design and communications course. It has proven to be an approach to design that makes sense from an engineering point of view. It allows for many levels of engagement, from pure external observation to deep and abstract levels of thinking. The field of biomimetics provides a great area for bridging the abstract concepts that are discussed in the pure science courses with the real world solutions that are necessary in engineering design. This area should be considered for first year curriculum in all engineering schools and has the potential to become a specialized minor in all areas of engineering.

\section{References}

[1] http://people.bath.ac.uk/en2ral/biomimeticprocess.html, accessed April 5, 2007.

[2]http://www.thinkcycle.org/tcfilesy stem/download/biomim icry_for_sustainable_innovation/thinkspace:_biomimetics_c ourse:_ocad_inds_3b22/concept__analysis_and_design_of _osc_biomimcry_exhibit/Material\%20World\%20Biomimicr y.html, accessed June 4, 2007.

[3] J.M. Benyus, Biomimicry Innovation Inspired by Nature, HarperCollins Publishers, New York, 1997, p. V.

[4] http://news.bbc.co.uk/2/hi/health/6729745.stm, accessed June 7, 2007

[5]http://news.nationalgeographic.com/news/2005/05/0511_ 050511_robots.html, accessed June 6, 2007.

[6] Benyus, p. 7.

[7] Compiled from http://database.biomimicry.org/

[8] http://www.gutenberg.org/files/10726/10726-h/10726h.htm, accessed June 7, 2007. 